\title{
Cerebrovascular Atherosclerosis in Type III Hyperlipidemia is Modulated by Variation in the Apolipoprotein A5 Gene
}

\author{
D. Evans' ${ }^{1}$, A. Bode ${ }^{1}$, G. von der Lippe 1 , F. U. Beil1, W. A. Mann ${ }^{2}$ \\ ${ }^{1}$ Endokrinologie und Stoffwechsel, Medizinische Klinik III, Zentrum für Innere Medizin, \\ Universitätsklinikum Hamburg-Eppendorf, Hamburg, Germany \\ ${ }^{2}$ Endokrinologikum, Frankfurt, Germany
}

\begin{abstract}
Objective: Type III Hyperlipoproteinemia is a rare lipid disorder with a frequency of $1-5$ in 5000 . It is characterized by the accumulation of triglyceride rich lipoproteins and patients are at increased risk of developping atherosclerosis. Type III HLP is strongly associated with the homozygous presence of the $\varepsilon 2$ allele of the $A P O E$ gene.

However only about $10 \%$ of subjects with APOE2/2 genotype develop hyperlipidemia and it is therefore assumed that further genetic and environmental factors are necessary for the expression of disease. It has recently been shown that variation in the $A P O A 5$ gene is one of these co-factors. The aim of this study is to investigate the development of cerebrovascular atherosclerosis in patients with Type III hyperlipoproteinemia (Type III HLP) and the role of variation in the APOA5 gene as a risk factor.

Methods: 60 patients with type III hyperlipidemia and ApoE2/2 genotype were included in the study after informed consent. The presence of cerebrovascular atherosclerosis was investigated using B-mode ultrasonography of the carotid artery. Serum lipid levels were measured by standard procedures. The APOE genotype and the 1131T $>C$ and S19W SNPs in the APOA5 gene and the APOC3 sstI SNP were determined by restriction isotyping. Allele frequencies were determined by gene counting and compared using Fisher's exact test. Continuous variables were compared using the Mann Whitney test. A p value of 0.05 or below was considered statistically significant. Analysis was performed using Statistica 7 software.

Results: The incidence of the APOA5 SNPs, $1131 \mathrm{~T}>\mathrm{C}$ and S19W and the APOC3 sstI SNP were determined as a potential risk modifier. After correction for conventional risk factors, the $\mathrm{C}$ allele of the $1131 \mathrm{~T}>\mathrm{C}$ SNP in the APOA5 gene was associated with an increased risk for the development of carotid plaque in patients with Type III HLP with an odds ratio of 3.69. Evaluation of the genotype distribution was compatible with an independent effect of APOA5.

Conclusions: The development of atherosclerosis in patients with Type III HLP is modulated by variation in the $A P O A 5$ gene.
\end{abstract}

Key words: Type III Hyperlipoproteinemia, Apolipo- protein A5, Apolipoprotein C3, atherosclerosis, gene variation

\section{INTRODUCTION}

Type III HLP is a rare disorder of lipid metabolism with a frequency of approximately 1-5 in 5000 and is characterized by the accumulation of triglyceride rich lipoprotein remnant particles in the form of $\beta$-VLDL and homozygosity for the $\varepsilon 2$ allele of the APOE gene [reviewed in 1]. Patients present with elevated and approximately equal levels of plasma cholesterol and triglycerides and are at increased risk of developing atherosclerosis. Almost all patients with Type III HLP are homozygous for the $\varepsilon 2$ allele of the APOE gene although only about $10 \%$ of subjects with APOE $2 / 2$ genotype develop the condition [1] and it is assumed that further genetic and/or environmental factors are necessary for the expression of disease. It has been shown that variation in the APOA5 gene is one of these co-factors [2, 3]. Apolipoprotein A5 (apoA5) contributes to triglyceride metabolism in both humans and animal models. In humans, apo A5 mutations show an association with elevated plasma triglyceride levels in most studies confirming the role of apoA5 in lipid metabolism. Family studies of apoA 5 variants indicated a variable mode of inheritance and a low penetrance of hyperlipidemia. Thus co-existence of other hyperlipidemic factors such as diabetes mellitus, environmental factors or additional disturbances in lipid metabolism are required for expression of hyperlipidemia.The recessive mode of inheritance and the low penetrance may explain why the results from human studies are not as clear as predicted from animal studies [4]. This is especially true for clinical consequences of hyperlipidemia: whereas some studies showed an association of apoA5 with atherosclerosis, others did not [5-11]. One explanation of the variable findings is the complex association of APOA5 variants with other apolipoprotein genes: the ApoA5 gene is part of the APOA/APOC3/APOA4/APOA5 gene cluster on chromosome 11q23. A number of studies, reviewed by Lai et al [12], have investigated the haplotype structure of this region. Whereas the APOA $5 * 3$ haplotype, defined by the S19W SNP, is independent of the APOC3 SNPs, the APOA5*2 haplotype defined by the $-1131 \mathrm{~T}>\mathrm{C}$ SNP is strongly associated with the 
APOC3 sstI SNP (rs5128) with $85 \%$ of the chromosomes with APOA $5 * 2$ containing the minor allele of sstI. It is therefore of interest to determine the frequency of the APOC3 sstI SNPs in order to evaluate the effect of variation in the APOA5 gene. Further insight into the role of apo A5 can be obtained by analysing well defined patient entities in order to restrict other variables. As it is unclear if the overrepresentation of ApoA5 variants in patients with Type III HLP is associated with increased atherosclerosis, we investigated this question in a patient collective with Type III HLP.

The aims of our study were therefore firstly to determine the incidence of atherosclerosis as determined by B-mode ultrasonography of the carotid artery and secondly to investigate the factors which lead to the development of carotid plaque in this high risk population with a special focus on $A P O A 5$ variants.

\section{METHODS}

\section{PARTICIPANTS}

Patients with mixed hyperlipidemia and APOE 2/2 genotype who have attended the lipid clinic, Universitätsklinikum Hamburg-Eppendorf, since 1997 were eligible for the study. Details of this patient group have been described previously [2, 13]. 60 patients with type III HLP were included into the study. All Probands gave informed consent and the study was approved by the Ethik-Kommission of the Ärztekammer Hamburg.

\section{Carotid Atherosclerosis}

To eliminate inter-operator variability, carotid b-mode ultrasonography was performed by a single trained sonographer unaware of the study design using a Vivid III expert from GE, using a 7,5 MHz transducer. Patients were measured bilatererally at three levels, following the protocol used in the Framingham study [14]. Intima-media thickness (IMT) is presented as the mean in $\mathrm{mm}$ of the measurements obtained for the common carotid artery (CCA) and the internal carotid artery (ICA). The common carotid arteries, both bifurcations and the internal carotid arteries were evaluated for the presence of plaque at the time of the ultrasound measurement.

\section{Biochemical MEASUREMENTS}

Plasma cholesterol (TC) and triglycerides (TG) were determined using the GPO-PAP and CHOD-PAP kits respectively from Boehringer Mannheim. HDL was determined following precipitation of apo B containing lipoproteins with phosphotungstate (Boehringer Mannheim). Lp(a) was determined using the Beckman Array 360 (Beckman Instruments).

\section{GENOTYPING}

The APOE genotype, the $1131 \mathrm{~T}>\mathrm{C}$ and S19W SNPs in the $A P O A 5$ gene, and the sstI SNP in the APOC3 gene were determined as described $[2,15,16]$.

\section{Statistical Methods}

Allele frequencies were determined by gene counting and compared using Fisher's exact test. Continuous variables were compared using the Mann Whitney test. A p value of 0.05 or below was considered statistically significant. Analysis was performed using Statistica 7 software.

\section{RESULTS}

The clinical characteristics of the individual patients are presented in Table 1. Plaque was detected in the carotid bulb in $25(42 \%)$ of patients. The mean IMT of patients with plaque was greater (ACC $0.88 \mathrm{~mm}$, bulb $1.40 \mathrm{~mm}$ ) than those without (ACC $0.75 \mathrm{~mm}$ bulb $0.99 \mathrm{~mm}), \mathrm{p}=0.0001$ for the difference in ACC and 0.00002 for the difference in the carotid bulb.

Comparing the incidence of the traditional risk factors for the development of atherosclerosis in Type III HLP patients with and without plaque there was no significant difference in the proportion of smokers/ex-smokers to never smokers, (15/25 and 24/35 respectively) or women $(8 / 25$ and $10 / 35)$. There were no significant differences in the levels of $\mathrm{Lp}(\mathrm{a})$ or in the occurrence of type 2 diabetes, (2/25 and 6/35), and hypertension, (8/25 and 7/35). Although, as is usual with Type III HLP, mean BMI was high there was no significant difference between patients with

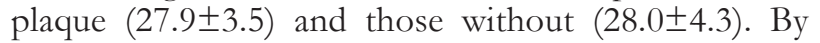
definition all patients had elevated plasma levels of total cholesterol and triglycerides. There were no significant differences in total cholesterol, triglycerides and HDL cholesterol between patient groups. However, comparison is difficult since for clinical reasons lipid lowering therapy could not be discontinued for a proportion of the patients. However for 16 patients with and 24 without plaque lipid values were obtained in the absence of lipid lowering therapy. Patients with plaque had higher total cholesterol, $400 \pm 174 \mathrm{mg} / \mathrm{dl}$ compared to patients without, 291 $124, \mathrm{p}=0.047$. There was no significant difference in triglyceride levels. No further subgroup analysis of lipid levels was performed due to small patient group size. Patients with plaque were significantly older, mean age 54 years compared to 46 years for those without, $\mathrm{p}=0.002$.

The frequency of the $-1131 \mathrm{~T}>\mathrm{C}$ SNP in $A P O A 5$ was compared in patients with plaque to that in those without (Table 2 a,b). The $\mathrm{C}$ allele was significantly more frequent in patients with plaque, $0.24(12 / 25)$, than in those without, $0.10(7 / 35), \mathrm{p}=0.035$. The odds ratio for carriers of the $\mathrm{C}$ allele to develop plaque was 3.69. In multiple regression analysis with presence or absence of plaque as dependent variable and age, BMI, smoking, hypertension, DM2, sex, $\mathrm{Lp}(\mathrm{a})$ and $A P O A 5-1131 \mathrm{~T}>\mathrm{C}$ genotype as independent variables only age $(\mathrm{p}=0.002)$ and $A P O A 5-1131 \mathrm{~T}>\mathrm{C}$ genotype $(\mathrm{p}=0.041)$ were significant factors. Inclusion of total cholesterol and triglycerides in the analysis but exclusion of patients from whom we had no lipid values in the absence of lipid lowering therapy ( $\mathrm{n}$ $=40$ ) reduced the significance of age, $\mathrm{p}=0.032$ and increased the significance of APOA5 genotype, $\mathrm{p}=$ 0.023 . No other factors were statistically significant. 
Table 1. Clinical characteristics of patients with bulbar plaque present or absent.

\begin{tabular}{|c|c|c|c|c|c|c|c|c|c|c|c|c|c|c|}
\hline $\begin{array}{l}\text { A) Plac } \\
\text { Pat } \\
\text { Num }\end{array}$ & $\begin{array}{l}\text { lue pre } \\
\text { AGE } \\
\text { years }\end{array}$ & $\begin{array}{l}\text { ent } \\
\text { SEX } \\
\mathrm{M} / \mathrm{F}\end{array}$ & $\begin{array}{l}\text { IMT } \\
\text { ACC } \\
\mathrm{mm}\end{array}$ & $\begin{array}{l}\text { IMT } \\
\text {-bulb } \\
\text { mm }\end{array}$ & $\begin{array}{l}\mathrm{Lp}(\mathrm{a}) \\
\mathrm{mg} / \mathrm{dl}\end{array}$ & $\begin{array}{l}\text { Smoker } \\
\mathrm{s} / \mathrm{ex} / \mathrm{n}\end{array}$ & $\begin{array}{l}\mathrm{D} \\
\mathrm{M} \\
2\end{array}$ & HT & KHK & AVK & CVI & Chol & Trig & $\mathrm{HDL}$ \\
\hline 101 & 37 & M & 0.75 & 0.90 & 105 & $\mathrm{~N}$ & - & - & - & - & - & 481 & 588 & 69 \\
\hline 76 & 41 & M & 0.93 & 1.83 & 6 & $\mathrm{Y}$ & - & + & - & + & - & 265 & 674 & 54 \\
\hline 90 & 44 & M & 0.75 & 0.88 & 54 & Y & - & - & + & - & - & 426 & 418 & 41 \\
\hline 36 & 44 & M & 0.67 & 1.45 & 2 & $\mathrm{Y}$ & - & - & - & - & - & 418 & 983 & 53 \\
\hline 35 & 45 & M & 0.70 & 1.50 & $<2$ & $\mathrm{EX}$ & - & + & + & + & - & 268 & 558 & 46 \\
\hline 44 & 45 & M & 0.83 & 1.48 & 3 & $\mathrm{Y}$ & - & - & - & - & - & 439 & 476 & 36 \\
\hline 28 & 47 & $\mathrm{M}$ & 0.85 & & 15 & $\mathrm{Y}$ & - & - & - & - & - & 316 & 634 & 53 \\
\hline 86 & 50 & $\mathrm{~F}$ & 0.80 & 0.95 & 2 & $\mathrm{Y}$ & - & - & - & - & - & 484 & 636 & 71 \\
\hline 63 & 50 & M & 0.78 & 1.10 & $<2$ & $\mathrm{~N}$ & - & - & - & - & - & 240 & 364 & 37 \\
\hline 4 & 52 & $\mathrm{~F}$ & 0.95 & 1.75 & 11 & $\mathrm{~N}$ & - & + & - & - & - & 651 & 433 & 44 \\
\hline 87 & 52 & M & 0.83 & 1.03 & $<2$ & $\mathrm{~N}$ & - & + & - & - & - & 182 & 418 & 41 \\
\hline 20 & 53 & $\mathrm{~F}$ & 1.08 & 1.90 & 4 & Y & - & - & - & - & - & 503 & 360 & 47 \\
\hline 45 & 53 & $\mathrm{M}$ & 0.95 & 1.00 & 8 & Y & - & - & - & + & - & 273 & 315 & 37 \\
\hline 71 & 55 & $\mathrm{M}$ & 1.10 & 1.60 & 3 & EX & - & + & - & - & + & 441 & 716 & 68 \\
\hline 27 & 55 & M & 0.95 & 1.45 & $<2$ & $\mathrm{~N}$ & + & + & + & - & - & 317 & 560 & 40 \\
\hline 48 & 55 & $\mathrm{~F}$ & 1.25 & 1.83 & $<2$ & $\mathrm{~N}$ & - & - & - & - & - & 428 & 460 & 42 \\
\hline 37 & 57 & $\mathrm{~F}$ & 0.90 & 1.43 & 11 & Y & - & - & - & - & - & 435 & 388 & 46 \\
\hline 52 & 59 & M & 1.08 & 1.63 & $<2$ & Y & - & - & - & - & + & 137 & 69 & 57 \\
\hline 38 & 48 & $\mathrm{M}$ & 0.83 & 1.23 & 15 & Y & - & - & - & - & - & 292 & 428 & 39 \\
\hline 93 & 61 & $\mathrm{~F}$ & & & 32 & Y & - & + & - & - & - & 341 & 777 & 33 \\
\hline 6 & 62 & $\mathrm{~F}$ & 0.70 & 1.05 & 22 & $\mathrm{~N}$ & - & - & - & - & - & 336 & 411 & 50 \\
\hline 16 & 62 & $\mathrm{M}$ & 0.80 & 1.13 & $<2$ & $\mathrm{~N}$ & - & - & - & - & - & 416 & 405 & 49 \\
\hline 89 & 65 & $\mathrm{M}$ & 0.83 & 1.28 & 9 & & - & - & + & - & - & 393 & 555 & 44 \\
\hline 3 & 69 & $\mathrm{M}$ & 0.92 & 2.15 & 10 & EX & - & + & & - & - & 331 & 548 & 41 \\
\hline 91 & 76 & $\mathrm{~F}$ & 0.90 & 1.55 & 7 & $\mathrm{~N}$ & + & & & & & & & \\
\hline Mean & 53.5 & & 0.88 & 1.40 & 13 & & & & & & & 367 & 507 & 47 \\
\hline $\mathrm{n}$ & 25 & $17 / 8$ & & & & $12 / 3 / 9$ & 2 & 8 & 4 & 3 & 2 & & & \\
\hline
\end{tabular}

\begin{tabular}{|c|c|c|c|c|c|c|c|c|c|c|c|c|c|c|}
\hline $\begin{array}{l}\text { B) Pla } \\
\text { Pat } \\
\text { Num }\end{array}$ & $\begin{array}{l}\text { AGe abs } \\
\text { years }\end{array}$ & $\begin{array}{l}\text { SEX } \\
\mathrm{m} / \mathrm{f}\end{array}$ & $\begin{array}{l}\text { IMT } \\
\text { ACC } \\
\mathrm{mm}\end{array}$ & $\begin{array}{l}\text { IMT- } \\
\text { Bulbus } \\
\mathrm{mm}\end{array}$ & $\mathrm{Lp}(\mathrm{a})$ & $\begin{array}{l}\text { Smoker } \\
\mathrm{s} / \mathrm{ex} / \mathrm{n}\end{array}$ & DM2 & HT & KHK & AVK & CVI & Chol & Trig & HDL \\
\hline 46 & 28 & M & 0.80 & 1.58 & 10 & $Y$ & - & - & - & - & - & 246 & 143 & 41 \\
\hline 100 & 30 & M & 0.73 & 1.05 & 19 & $\mathrm{Y}$ & - & - & - & - & - & 694 & 1118 & 44 \\
\hline 40 & 31 & M & 0.77 & 0.80 & 4 & $\mathrm{Y}$ & - & - & - & - & - & 201 & 261 & 29 \\
\hline 72 & 32 & M & 0.67 & 0.85 & 3 & & - & - & - & - & - & 446 & 729 & 51 \\
\hline 33 & 34 & M & 0.70 & 0.88 & 7 & $\mathrm{Y}$ & - & - & - & - & - & & & \\
\hline 62 & 36 & M & 0.60 & 0.67 & 10 & $\mathrm{~N}$ & - & - & - & - & - & 202 & 177 & 65 \\
\hline 60 & 37 & M & 0.67 & 1.05 & 3 & Y & - & - & - & - & - & 225 & 293 & 37 \\
\hline 65 & 38 & $\mathrm{~F}$ & 0.72 & 0.93 & $<2$ & EX & - & + & - & - & - & 377 & 949 & 40 \\
\hline 97 & 38 & M & 0.60 & 0.83 & 2 & EX & - & - & - & - & - & 408 & 402 & 69 \\
\hline 21 & 39 & M & 0.70 & 0.98 & 3 & Y & - & - & - & - & - & 143 & 266 & 32 \\
\hline 73 & 39 & $\mathrm{~F}$ & 0.75 & 0.88 & 10 & $\mathrm{EX}$ & - & - & - & - & - & 579 & 519 & 55 \\
\hline 102 & 40 & M & 0.78 & 0.93 & 19 & $\mathrm{~N}$ & - & - & - & - & - & 196 & 165 & 52 \\
\hline 5 & 41 & $\mathrm{~F}$ & 0.65 & 0.65 & 27 & $\mathrm{~N}$ & + & - & - & - & - & 598 & 939 & 57 \\
\hline 14 & 41 & $\mathrm{~F}$ & 0.73 & 0.98 & 9 & EX & - & - & - & - & - & 255 & 120 & 63 \\
\hline 50 & 42 & M & 0.68 & 1.05 & 15 & $\mathrm{EX}$ & - & + & + & - & - & 251 & 407 & 29 \\
\hline 8 & 42 & M & 0.65 & 0.65 & $<2$ & $\mathrm{Y}$ & - & - & - & - & - & 154 & 258 & 41 \\
\hline 95 & 42 & $\mathrm{~F}$ & 0.90 & 1.55 & 11 & EX & - & + & + & - & - & 286 & 473 & 35 \\
\hline 61 & 43 & M & 0.63 & 0.92 & 4 & EX & - & - & - & - & - & 360 & 678 & 57 \\
\hline 12 & 43 & M & 0.80 & 0.98 & 7 & $\mathrm{Y}$ & - & - & - & - & - & 149 & 92 & 56 \\
\hline 64 & 44 & M & 0.80 & 0.73 & 17 & $\mathrm{Y}$ & + & + & - & - & - & 444 & 932 & 49 \\
\hline 47 & 47 & M & 0.78 & 0.95 & 4 & $\mathrm{~N}$ & - & - & - & - & - & 483 & 641 & 35 \\
\hline 85 & 47 & M & 0.73 & 0.78 & $<2$ & EX & - & - & - & - & - & 380 & 727 & 50 \\
\hline 94 & 48 & M & 1.05 & 1.03 & $<2$ & $\mathrm{~N}$ & - & + & - & - & - & 285 & 313 & 54 \\
\hline 11 & 50 & M & 0.77 & 0.93 & 14 & $\mathrm{Y}$ & - & - & - & - & - & 343 & 513 & 40 \\
\hline 1 & 50 & $\mathrm{~F}$ & 0.60 & 0.85 & 8 & Y & - & - & - & - & - & 532 & 311 & 57 \\
\hline 53 & 51 & M & 0.92 & 1.00 & 49 & EX & - & - & + & - & - & 252 & 198 & 41 \\
\hline 25 & 51 & M & 0.70 & 0.98 & $<2$ & & - & + & - & - & - & 414 & 682 & 38 \\
\hline 98 & 56 & M & & 0.70 & $<2$ & $\mathrm{Y}$ & + & - & - & - & - & 399 & 762 & 48 \\
\hline 34 & 56 & F & 0.77 & 1.40 & 8 & EX & + & - & + & - & - & 665 & 1640 & 78 \\
\hline 59 & 58 & M & 0.85 & 1.30 & $<2$ & $\mathrm{~N}$ & - & - & - & - & - & 204 & 282 & 62 \\
\hline 31 & 60 & $\mathrm{~F}$ & 0.80 & 1.05 & 52 & $\mathrm{~N}$ & - & - & - & - & - & 397 & 283 & 70 \\
\hline 23 & 61 & M & 0.73 & 1.03 & 56 & EX & + & + & - & - & - & 442 & 709 & 50 \\
\hline 74 & 63 & $\mathrm{~F}$ & 0.80 & 1.23 & 15 & EX & - & - & - & - & - & 211 & 323 & 42 \\
\hline 70 & 70 & $\mathrm{~F}$ & 0.83 & 1.43 & 13 & $\mathrm{~N}$ & - & - & - & - & - & 473 & 609 & 65 \\
\hline 66 & 74 & M & 0.85 & 1.08 & 5 & $\mathrm{~N}$ & + & - & + & - & + & 276 & 752 & 56 \\
\hline Mean & 46 & & 0.75 & 0.99 & 12 & & & & & & & 354 & 558 & 50 \\
\hline $\mathrm{n}$ & 35 & $25 / 10$ & & & & $12 / 12 / 10$ & 6 & 7 & 5 & 0 & 1 & & & \\
\hline
\end{tabular}

Patients are listed in order of increasing age. $+=$ presence of DM2 or hypertension $(\mathrm{HT})$; IMT in mm; Lp(a) in mg/dl 
Table 2. APOA5 and APOC3 polymorphism frequencies in patients with bulbar plaque present or absent.

\begin{tabular}{|c|c|c|c|c|c|c|c|c|}
\hline \multicolumn{4}{|c|}{ A) Plaque present } & \multirow{2}{*}{\multicolumn{5}{|c|}{$\begin{array}{l}\text { C: Summary of APOA5 and APOC3 polymorphism fre- } \\
\text { quencies }\end{array}$}} \\
\hline Pat & APOC3 & APOA5 & APOA5 & & & & & \\
\hline Num & $\begin{array}{l}\text { sstI } \\
\text { rs5128 }\end{array}$ & $\begin{array}{l}1131 \mathrm{~T}>\mathrm{C} \\
\mathrm{rs} 662799\end{array}$ & $\begin{array}{l}\text { S19W } \\
\text { rs3135506 }\end{array}$ & $\begin{array}{l}\text { APOC3 } \\
\text { sstI }\end{array}$ & $\begin{array}{l}\text { APOA5 } \\
-1131 T>C\end{array}$ & $\begin{array}{l}\text { APOA5 } \\
\text { S19W }\end{array}$ & $\begin{array}{l}\text { Plaque } \\
\text { Present }\end{array}$ & $\begin{array}{l}\text { Plaque } \\
\text { Absent }\end{array}$ \\
\hline 101 & & & & GG & TT & SS & 9 & 18 \\
\hline 76 & & & & GG & TC & SS & 2 & 4 \\
\hline 90 & GC & TC & & GG & T'T & SW & 4 & 5 \\
\hline 36 & & TC & & GG & TC & SW & 0 & 2 \\
\hline 35 & & & & GG & TT & WW & 0 & 1 \\
\hline 44 & GC & TC & & & & & & \\
\hline 28 & & & & GC & TT & SS & 0 & 4 \\
\hline 86 & & & SW & GC & TC & SS & 9 & 1 \\
\hline 63 & GC & TC & & GC & TC & SW & 1 & 0 \\
\hline
\end{tabular}

There was no significant difference in the frequency of the W allele of the S19W SNP between patients with plaque 0.10 and those without 0.14 . The frequency of the minor allele of the APOC3 sstI SNP was significantly higher in Type III HLP patients with plaque, 0.2 , compared to those without, 0.07 ( $\mathrm{p}=$ 0.03, Fisher's exact, two-tailed, Table 2c). Comparing the distribution of the genotypes APOC3GG/ APOA5T'T/APOA5SS and APOC3GC/APOA5TC/ APOA5SS amongst patients with or without plaque, we found an equal distribution in patients with plaque, 9 with each genotype whereas in patients without plaque there was only one double heterozygote compared to 18 with the common haplotype ( $p=0.003$, Fisher's exact, two-tailed). All four patients with genotype APOC3GC/APOA5TT/APOA5SS did not have plaque.

\section{Discussion}

The principal finding of this investigation is that the $1131 \mathrm{~T}>\mathrm{C}$ SNP in the APOA5 gene is a risk factor for the development of carotid plaque in patients with Type III HLP. Although this SNP has been consistently associated with elevated triglycerides and lower HDL in a number of studies [13, 17-20], its association with the development of atherosclerosis has been inconsistent with positive associations being reported in some, but not all studies [5-12]. The inconsistent results reported may be explained by a relatively modest functional influence of such a common genetic variant and by the recessive mode of disease expression as well as inheritance. These characteristics of apoA 5 will result in considerable genetic and phenotypic variability in the population under study. With this background a major advantage of our study is that Type III HLP patients represent a well-defined, homogeneous group. This patient collective has a number of conventional risk factors in common providing a uniform background in which to investigate the role of variants in candidate genes. By investigating patients with the same $A P O E$ genotype one source of genetic variability is eliminated. This applies not only to the reduction of variability for dyslipidemia but also for the clinical consequence of atherosclerosis since the APOE genotype has been associated in a number of studies with carotid phenotype [reviewed in 21].

Although APOE 2/2 genotype is required for the development of Type III HLP only approximately 
$10 \%$ of $A P O E 2 / 2$ subjects suffer from the condition implying that additional genetic and/or environmental factors are necessary for its expression [1]. We suggest that variation of apoA 5 may be one of these factors not only for expression of hyperlipidemia [2] but also for the clinical endpoint of atherosclerosis. How could apoA 5 modulate disease expression in type III HLP ? It has been shown that apoA5 upregulates lipolysis by binding to heparin sulphate proteoglycans (HSPG, [22]). The interaction of apoE with HSPG plays an important role for the expression of type III HLP in addition to its reduced binding to lipoprotein receptors [23]. We postulate that intact apoA5 may be able to at least in part compensate the reduced HSPG interaction of ApoE2, whereas apoA5 variants with either reduced synthesis or structural defects may not, thus resulting in the necessary second defect for expression of type III HLP. Proof of this principle has been shown for lipoprotein lipase (LPL) variants, where defects in LPL were detected in patients with type III HLP as second dyslipidemic factor in addition to the presence of apoE 2 [24]. Recent in vitro structure - function analysis of apoA5 variants is compatible with the postulated coordinated interaction of apoE, LPL and apoA5 [25]. These variants, which do not induce hyperlipidema in isolated form or may not be identifiable as risk factor in a unselected population, may be unmasked in combination with variants in other target genes as in the presented study. In case of the $1131 \mathrm{~T} / \mathrm{C}$ exchange, which is located in the promotor region of ApoA5 reduced synthesis of apoA5 may result in decreased protein levels and thus reduced coordinated protein-protein or protein-HSPG interactions. Alternatively synthesis rates may be influenced by the $A>G$ exchange at position -3 , which is linked to the $1131 \mathrm{~T} / \mathrm{C}$ exchange as part of the APOA5*2 haplotype. Results from in vitro expression studies do not show a functional effect of the single variant, however a cooperative effect of these variants on protein synthesis cannot be ruled out [26]. In addition the APOA $5 * 2$ haplotype is in significant linkage disequilibrium with the sstI polymorphism and two promotor variants in the APOC3 gene, the $482 \mathrm{~T}$ and the $-455 \mathrm{C}$ allele [27]. These variants are located in the insulin responsive element of the promotor region of the APOC 3 gene and are associated with plasma triglyceride levels [28]. To evaluate the separate effects of variation in the $A P O A 5$ and $A P O C 3$ gene it is therefore important to determine the frequency of the APOC3 sstI SNP in our Type III HLP patients in addition to the analysis of the $1131 \mathrm{~T} / \mathrm{C}$ exchange. The frequency of the minor allele of the APOC3 sstI SNP was significantly higher in Type III HLP patients with plaque, 0.2, compared to those without, 0.07 ( $p=0.03$, Fisher's exact, twotailed), which is not unexpected and reflects the linkage of the alleles as part of the APOA $5 * 2$ haplotype. In order to dissect the effects of the GC allele in APOC3 and the TC allele in APOA5 the distribution of the genotypes APOC3GG/APOA5TT/APOA5SS and APOC3GC/APOA5TC/APOA5SS amongst patients with or without plaque was analysed. Both variant alleles were significantly more frequent in patients with plaque as compared to patients without plaque. However the presence the GC allele was not associated with plaque, when combined with a TT allele, whereas a significant association of the GC allele with plaque was obeserved in the presence of a TC allelle. These data imply that it is the $1131 \mathrm{~T} / \mathrm{C}$ exchange in the $A P O A 5$ gene which is associated with plaque in patients with Type III HLP.

The major weakness of our study is the small number of patients available for analysis. This is due to the rarity of Type III HLP, (in our clinic 72/2545 patients attending over a ten year period), with a frequency of Type III HLP of 1-5 in 5000. The 60 patients included in this study therefore represent an estimated population of 60,000-300,000. Confirmation of our findings in other populations is necessary. The analysis of the frequency of candidate SNPs for atherosclerosis in a small but homogeneous patient group adds important information to studies in large more heterogeneous groups when investigating the effect of common polymorphisms on complex traits such as atherosclerosis.

\section{CONCLUSION}

In conclusion we present evidence that $-1131 \mathrm{~T}>\mathrm{C}$ $\mathrm{SNP}$ in the $A P O A 5$ gene influences the development of coronary plaque in a group of patients at high risk, namely those with Type III HLP indicating a role of apoA 5 not only in dyslipidemia but also in the pathophysiology of atherosclerosis.

Competing interests: The authors declare that they have no competing interests.

\section{REFERENCES}

1. Mahley RW, and Rall SC: Type III Hyperlipoproteinemia (Dysbetalipoproteinemia): The role of apolipoprotein E in normal and abnormal lipoprotein metabolism. In The Metabolic and molecular bases of inherited disease. 8th Edition. Scriver et al (ed). 2835-2862. McGraw Hill. New York. 2001

2. Evans D, Seedorf U, Beil FU: Polymorphisms in the apolipoprotein A5 (APOA5) gene and type III hyperlipidemia. Clinical Genetics. 2005, 68: 369-372.

3. Schaefer EJ, Sattler AM, Hackler B, Kurt B, Hackler R, Maisch B and Soufi M: Hyperlipidemia in Patients with Apolipoprotein E 2/2 Phenotype: Apolipoprotein A5 S19W Mutation as a Cofactor. Clinical Chemistry 2004, 50: 2214.

4. Talmud PJ: Rare APOA5 mutations-clinical consequences, metabolic and functional effects: an ENID review. Atheroscerosis 2007, 194(2): 287-292.

5. Hubacek JA, Skodová Z, Adámková V, Lánská V, Poledne R: The influence of APOAV polymorphisms ( $T$ $1131>C$ and $\mathrm{S} 19>\mathrm{W}$ ) on plasma triglyceride levels and risk of myocardial infarction. Clin Genet 2004, 65: 126130.

6. Szalai C, Keszei M, Duba J, Prohászka Z, Kozma GT, Császár A, Balogh S, Almássy Z, Fust G, Czinner A: Polymorphism in the promoter region of the apolipoprotein A5 gene is associated with an increased susceptibility for coronary artery disease. Atherosclerosis 2004; 173: 109-114.

7. Talmud PJ, Martin S, Taskinen MR, Frick MH, Nieminen MS, Kesäniemi YA, Pasternack A, Humphries SE, Syvänne M: APOA5 gene variants, lipoprotein particle distribution, and progression of coronary heart disease: results from the LOCAT study. J Lipid Res 2004, 45: 750756. 
8. Lai CQ, Demissie S, Cupples LA, Zhu Y, Adiconis X, Parnell LD, Corella D, Ordovas JM: Influence of the APOA5 locus on plasma triglyceride, remnant-like particles, lipoprotein subclasses and cardiovascular disease risk in the Framingham Heart Study. J Lipid Res 2004, 45: 2096-2105.

9. Lee KW, Ayyobi AF, Frohlich JJ, Hill JS.: APOA5 gene polymorphism modulates levels of triglyceride, HDL cholesterol and FERHDL but is not a risk factor for coronary artery disease. Atherosclerosis 2004, 176: 165-172.

10. Bi N, Yan SK, Li GP, Chen BS: A single nucleotide polymorphism -1131 $\mathrm{T}>\mathrm{C}$ in the apolipoprotein A5 gene is associated with an increased risk of coronary artery disease and alters triglyceride metabolism in Chinese. Mol Genet Metab 2004, 83: 280-285.

11. Liu H, Zhang S, Lin J, Li H, Huang A, Xiao C, Li X, Su Z, Wang C, Nebert DW, Zhou B, Zheng K, Shi J, Li G, Huang D: Association between DNA variants in the apolipoprotein A5 gene and coronary heart disease in Chinese. Metabolism 2005, 54(5): 568-572.

12. Lai CQ, Parnell LD, Ordovas JM: The APOA1C3/ A4/A5 gene cluster, lipid metabolism and cardiovascular disease risk. Current Opinion in Lipidology 2005, 16 : 153-166.

13. Evans D, Buchwald A, Beil FU: The single nucleotide polymorphism $-1131 \mathrm{~T}>\mathrm{C}$ in the apolipoprotein A5 (APOA5) gene is associated with elevated triglycerides in patients with hyperlipidemia. J Mol Med 2003, 81: 645654.

14. Fox CS, Polak JF, Chazaro I, Cupples A, Wolf PA, D'Agostino RA, O'Donnell CJ: Genetic and environmental contributions to atherosclerosis phenotypes in men and women. Heritability of carotid intima-media thickness in the Framingham Heart Study. Stroke 2003, 34:397-401

15. Hixson JE, Vernier DT.: Restriction isotyping of human apolipoprotein $\mathrm{E}$ by gene amplification and cleavage with Hha I. J Lipid Res 1990, 31:545-8.

16. Waterworth DM, Ribalta J, Nicaud V, Dallongeville J, Humphries SE, Talmud P. ApoCIII gene variants modulate postprandial response to both glucose and fat tolerance tests. Circulation 1999, 99(14): 1872-7.

17. Talmud P, Hawe E, Martin S, Oliver M, Miller GJ, Rubin EM, Pennacchio LA, Humphries SE.: Relative contribution of variation within the APOC3/A4/A5 gene cluster in determining plasma triglycerides. Hum Mol Genet 2002, 11:3039-3046.

18. Ribalta J, Figuera L, Fernández-Ballart J, Vilella E, Cabezas MC, Masana L, Joven J.: Newly identified apolipoprotein AV gene predisposes to high plasma triglycerides in familial combined hyperlipidemia. Clinical Chemistry 2002, 48:1597-1600.

19. Nabika T, Nasreen S, Kobayashi S, Masuda J.: The genetic effect of the apoprotein AV gene on serum triglyceride level in Japanese. Atherosclerosis 2002, 165:201-204.
20. Endo K, Yanagi H, Araki J, Hirano C, Yamakawa-Koybayashi K, Tomura S.: Association found between the promoter region polymorphism in the apolipoprotein A$\mathrm{V}$ gene and the serum triglyceride level in Japanese schoolchildren. Hum Genet 2002, 111:570-572.

21. Manolio TA, Boerwinkle E, O'Donnell CJ, Wilson AF: Genetics of ultrasonographic carotid atherosclerosis. Arterio Thromb Vasc Biol 2004, 24: 1567-1577.

22. Merkel M, Loeffler B, Kluger M, Fabig N, Geppert G, Pennacchio LA, Laatsch A, Heeren J.: Apolipoprotein AV accelerates plasma hydrolysis of triglyceride-rich lipoproteins by interaction with proteoglycan-bound lipoprotein lipase. J Biol Chem 2005, 280(22):21553-60.

23. Mann WA, Meyer N, Berg D, Greten H, Beisiegel U.: Lipoprotein lipase compensates for the defective function of apo $\mathrm{E}$ variants in vitro by interacting with proteoglycans and lipoprotein receptors. Atherosclerosis 1999, 145(1):61-9.

24. Brümmer D, Evans D, Berg D, Greten H, Beisiegel U, Mann WA.:Expression of type III hyperlipoproteinemia in patients homozygous for apolipoprotein E-2 is modulated by lipoprotein lipase and postprandial hyperinsulinemia. J Mol Med 1998, 76(5):355-64

25. Dorfmeister B, Zeng WW, Dichlberger A, Nilsson SK, Schaap FG, Hubacek JA, Merkel M, Cooper JA, Lookene A, Putt W, Whittall R, Lee PJ, Lins L, Delsaux N, Nierman M, Kuivenhoven JA, Kastelein JJ, Vrablik M, Olivecrona G, Schneider WJ, Heeren J, Humphries SE, Talmud PJ.: Effects of six APOA5 variants, identified in patients with severe hypertriglyceridemia, on in vitro lipoprotein lipase activity and receptor binding. Arterioscler Thromb Vasc Biol 2008, 28(10):1866-71.

26. Talmud PJ, Palmen J, Putt W, Lins L, Humphries SE. Determination of the functionality of common APOA5 polymorphisms. J Biol Chem 2005, 280(31):28215-20.

27. Olivier M, Wang X, Cole R, Gau B, Kim J, Rubin EM, Pennacchio LA.: Haplotype analysis of the apolipoprotein gene cluster on human chromosome 11. Genomics 2004, 83: 912-23.

28. Groenendijk M, Cantor RM, Bruin TWA, Dallinga-Thie GM: The apoAI-CIII-AIV gene cluster. Atherosclerosis 2001, 157:1-11.

Received: Ma 18, 2010 / Accepted: October 19, 2010

Address for correspondence:

W. A. Mann

Endokrinologikum Frankfurt

Stresemannallee 3

60596 Frankfurt

Germany

Tel.: (49) 69-6959792420

Fax: (49) 69-6959792466

E-mail: alexander.mann@endokrinologikum.com 